\title{
A Critical Assessment of Skills and Knowledge for Entry-Level Marketing Jobs: A Delphi Study: An Abstract
}

\author{
Poh-Lin Yeoh
}

\begin{abstract}
Despite widespread attempts to compile lists of employability skills and competencies, there has not been a clear consensus on which soft skills, in particular, are most critical for employability. This is not unexpected given that each field of study has its own interpretation of epistemology and goal outcomes. Given that the importance of technical and soft skills may differ by specific context, the goal of this study is to identify the skill set that marketing undergraduates need for employability and to develop into a successful professional.

While the marketing education literature has contributed to our understanding of the skills that may be important for marketing undergraduates to possess (e.g., Schlee and Harich 2010; Schlee and Karns 2017), there remain two important gaps in the literature that this study seeks to address: first, there is limited effort to study both technical and soft skills together and, second, their relative importance for employability among marketing undergraduates. We address these gaps by conducting a Delphi study with a panel comprising of 12 human resource managers and 15 marketing managers.

Among the list of 51 skills identified in the initial brainstorming stage, the panelists selected 20 skills as being the most critical for entry-level marketing jobs and then ranked them on their relative importance. When consensus was established after three rounds, the five most important skills in chronological order were (1) application of marketing concepts/tools, (2) verbal communication skills, (3) creative problem-solving, (4) research aptitude and written communication skills, and (5) knowledge of company's products. Follow-up interviews were conducted with selected panelists to gain insights into the top five skills identified in the Delphi study. Finally, we compared our results with three different industry studies and discuss their implications for marketing education.
\end{abstract}

References Available Upon Request

\author{
P.-L. Yeoh $(\bowtie)$ \\ Bentley University, Waltham, MA, USA \\ e-mail: pyeoh@bentley.edu
}

